\title{
Peripheral Neuropathy
}

National Cancer Institute

\section{Source}

National Cancer Institute. Peripheral Neuropathy. NCI Thesaurus. Code C119734.

A disorder affecting the peripheral nervous system. It manifests with pain, ting ling,

numbness, and muscle weakness. It may be the result of physical injury, toxic substances,

viral diseases, diabetes, renal failure, cancer, and drugs. 